$\mathbb{T}$ periodica polytechnica

Civil Engineering

$58 / 1(2014) 71+85$

doi: $10.3311 / P$ Pci.7407

http://periodicapolytechnica.org/ci

Creative Commons Attribution (i)

RESEARCH ARTICLE

\section{Analysis of on- and off-ramp types on highways}

Attila Kollár

Received 2013-01-22, revised 2013-02-28, accepted 2013-03-05

\begin{abstract}
In this course of my current research, it is my intention to highlight how the most capacity-sensitive elements of highways should be designed in the function of traffic flow, exit and entry traffic flow and traffic composition. In addition to this, I also analyze whether it is sufficient - on the basis of the simulation test results - to design, and then to implement shorter or longer merging and diverging lanes.
\end{abstract}

\section{Keywords}

rural highway expressway sections $\cdot$ highwayramps $\cdot$ merging (acceleration) and diverging (deceleration) lanes $\cdot$ traffic simulation · VISSIM

\section{Attila Kollár}

Department of Highway and Railway Engineering, Budapest University of Technology and Economics, Múegyetem rkp. 3, H-1111 Budapest, Hungary e-mail: kollar@uvt.bme.hu

\section{Introduction}

Higways, Expressways and their interchangejunctions are the most expensive elements of our public road network. The method of building interchangejunction elements largely influences the operation of the highway network, however, it is necessary to seek the optimal arrangement where the traffic needs are satisfied but there is no excessive reserve on the side of investment costs. The number of passing vehicles reduces in the neighborhood of highway elements. This impact diminishes from the nearside (right-hand) lanes towards the offside (lefthand) lanes. The section where the impact of the ramp element on the running track (between interchanges) can be indicated is called the influence area. In my analysis I am trying to specify the influence area of various junction elements. In addition to this, I also make an attempt to determine what type of junction element is expedient to apply for what traffic flow, traffic composition as well as for what merging and diverging traffic rate, thus providing the opportunity to keep the increasing investment costs under control.

This analysis can be carried out with up-to-date, computerized simulation programs [1] - I used the VISSIM program, which was developed by PTV Ag.

Prior to explaining the carried out surveys and the results, let me briefly touch upon the design practice followed in Hungary and in the USA.

\section{Highlights on the Hungarian design practice}

The relevant Hungarian design guide TÚ [6] covers the construction of exits and entries, but it does not classify them according to further aspects.

According to the guide, the K1 type, simple off-lane with deceleration lane is the most frequent solution for exits. The TÚ guide recommends $\mathrm{K} 2$ type (off-ramp with two lanes) if the traffic needs do not change compared to the former case, but twolane cross-section is required either due to the length of the interchange ramp, or due to other factors. For traffic-related reasons, the TÚ guide recommends the K3 type (off-ramp with two lanes and with longer lane change sections) design for ramps with 2lane cross-section and in the case of unchanged traffic load on 
the running track. K4 type exit (off-ramp with two lanes with longer lane change section and with one lane exit) can be applied if the cross-section can be reduced after the exit due to the traffic load.

In addition, the TÚ guide specifies the diverging lane length to be applied in function of the design speed of the running track and the connecting junction branch as well as the decline/ascent of the running track length. According to the relevant table, the shortest length of the diverging lane (to be understood together with changing lanes and deceleration) is $180 \mathrm{~m}$, and the recommended maximum length is $380 \mathrm{~m}$. However, the TÚ guide does not specify which exit type should be applied for what traffic flows.

For entries, the applicability of the various entry types is defined in a manner similar to exits. However, apart from the textual description, there is also a graph (see Figure 1), where the applicable entry type can be specified in function of the lane traffic of the main track and the traffic flow planned for entry (in both cases it is expressed as $\mathrm{c} / \mathrm{h} /$ lane). The off-ramp lane length is set at $380 \mathrm{~m}$, and the in the case of longer lane change section lane length is set at $1000 \mathrm{~m}$.

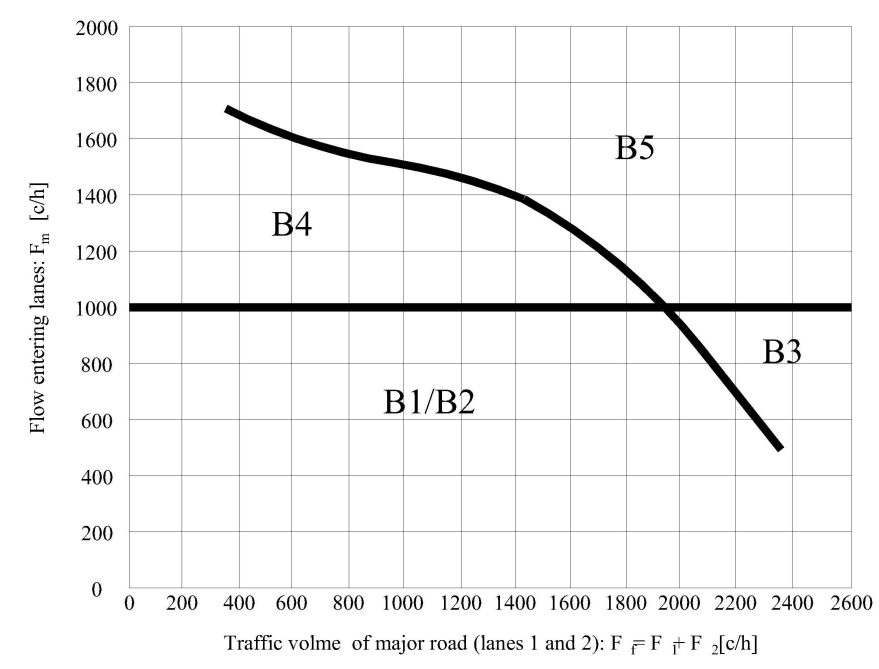

Fig. 1. Diagram of the TÚ Guide specifying the entry design

The above description goes to show that - apart from selecting the junction element type - the domestic practice gives no further assistance about what service level the already existing junction elements offer, which could help to forecast an eventual capacity extension.

\section{Highlights on the American (HCM) design practice}

The American design practice [8] covers in details the service level of highway ramps. It specifies the distance where the merging and diverging traffic exerts an impact on the main track traffic. This distance is called influence area. Based on research, the HCM specifies this influence area in $450 \mathrm{~m}$, calculated backwards from the separation point of the main track and the ramp. The influence area mostly affects lanes 1 and 2, as practical experience shows that vehicles nearing the exit use lane
1, so the exiting drivers go to the right, and those who continue on the highway change for the free, offside (left-hand) lanes in order to bypass the vehicles that are eventually travelling at a lower speed due to the lane-changing maneuver. In the case of entry, the influence area length is also $450 \mathrm{~m}$, to be calculated backwards from the connection point of the main track and the merging lane.

The connection of the diverging lane and the main track is classified through the service level that can be found on the A-F scale, where level F represents the status where there is already a traffic jam, so capacity extension is definitely required. The service level is determined by the vehicle density in the influence area. The density gives the number of vehicles at a length of 1 $\mathrm{km}$ in the lane $[\mathrm{pc} / \mathrm{km} / \mathrm{lane}]$.

Steps to define the service level:

- the traffic must be determined in lanes 1 and 2 in terms of car units $\left(\mathrm{v}_{12}\right)$;

- the traffic entering the influence area must be compared to the maximum number of vehicles that are able to move (entry: $\mathrm{v}_{\mathrm{R} 12}$, exit: $\mathrm{v}_{12}$ );

- the maximum traffic size must be compared to the capacity (entry: $\mathrm{v}_{\mathrm{FO}}$, exit: $\mathrm{v}_{\mathrm{FO}}+\mathrm{v}_{\mathrm{R}}$ );

- the influence area density $\left(D_{R}\right)$ must be specified, and then the service level can be determined.

The above listed markings are indicated in Figure 2.

In case of exits the service level is specified through the formula (1) and (2):

$$
v_{12}=v_{\mathrm{R}}+\left(v_{\mathrm{F}}-v_{\mathrm{R}}\right) \times P_{\mathrm{FD}}
$$

where:

- $v_{12}=$ flow rate in Lanes 1 and 2 of freeway immediately upstream of diverge $[\mathrm{pc} / \mathrm{h}]$,

- $v_{\mathrm{R}}=$ off-ramp demand flow rate $[\mathrm{pc} / \mathrm{h}]$,

- $v_{\mathrm{F}}=$ freeway demand flow rate immediately upstream of diverge $[\mathrm{pc} / \mathrm{h}]$

- $P_{\mathrm{FD}}=$ is the rate of vehicles staying in lanes 1 and 2 before the diverging lane.

The value of $P_{\mathrm{FD}}$ is 1 on 4-lane highways, and the HCM calculation method includes 4 equations for specifying the $P_{\mathrm{FD}}$ on 6- and 8-lane highways, and these consider the lane number of the half cross-section, as well as the distance and the traffic flow of the neighboring exits and entries.

$$
D_{\mathrm{R}}=2,642+0,0053 \times v_{12}-0,0183 \times L_{\mathrm{D}}
$$

where:

- $D_{\mathrm{R}}=$ density of diverge influence area $[\mathrm{pc} / \mathrm{km} / \mathrm{ln}]$, 


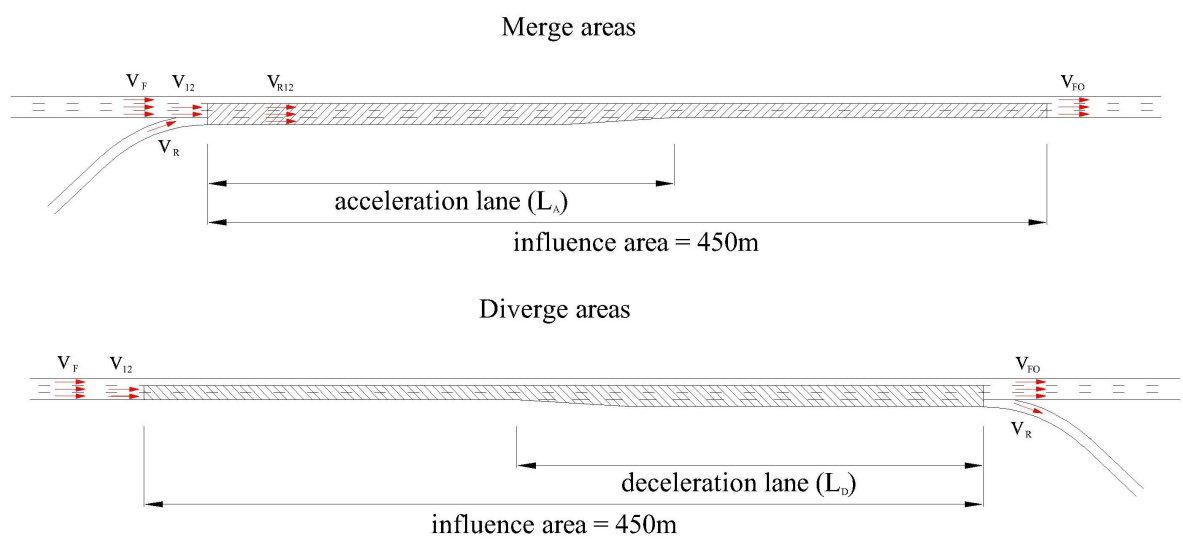

Fig. 2. Explanation of the HCM markings in the case of entry and exit

- $v_{12}=$ flow rate entering ramp influence area $[\mathrm{pc} / \mathrm{h}]$,

- $L_{\mathrm{D}}=$ stands for the length of the diverging lane [m].

The formula (2) goes to show that the length of the diverging lane reduces the influence area density, thus the service level also improves with the length of the diverging lane.

In case of entries, the service level is specified through the formula (3) and (4):

$$
v_{12}=v_{\mathrm{F}} \times P_{\mathrm{FM}}
$$

where:

- $v_{12}=$ flow rate in Lanes 1 and 2 of freeway immediately upstream of merge $[\mathrm{pc} / \mathrm{h}]$,

- $v_{\mathrm{F}}=$ freeway demand flow rate immediately upstream of merge $[\mathrm{pc} / \mathrm{h}]$,

- $P_{\mathrm{FM}}=$ is the rate of vehicles staying in lanes 1 and 2 before the merging point.

The value of $P_{\mathrm{FM}}$ is 1 on 4-lane highways, and the HCM calculation method includes 4 equations for specifying the $P_{\mathrm{FD}}$ on 6- and 8-lane highways, and these consider the lane number of the half cross-section, as well as the distance and the traffic flow of the neighboring exits and entries.

$$
D_{\mathrm{R}}=3,402+0,00456 \times v_{\mathrm{R}}+0,0048 \times v_{12}-0,01278 \times L_{\mathrm{A}}
$$

where:

- $D_{\mathrm{R}}=$ density of merge influence area $[\mathrm{pc} / \mathrm{km} / \mathrm{ln}]$,

- $v_{\mathrm{R}}=$ on-ramp peak $15-\mathrm{min}$ flow rate $[\mathrm{pc} / \mathrm{h}]$,

- $v_{12}=$ flow rate entering ramp influence area $[\mathrm{pc} / \mathrm{h}]$,

- $L_{\mathrm{A}}=$ stands for the length of the merging lane [m].

Similarly to exits, the influence area density also reduces in the case entries, and, together with this, the service level improves with the increase of the merging lane length.

Based on the $D_{\mathrm{R}}$ vehicle density, the service level of entry and exit can be defined according to table 3 that is featured in Figure 3

\begin{tabular}{cc}
\hline $\begin{array}{c}\text { Level of services } \\
\text { (LOS) }\end{array}$ & $\begin{array}{c}\text { Density } D_{\mathrm{R}} \\
\text { [pc/km/ln] }\end{array}$ \\
\hline $\mathrm{A}$ & $D_{\mathrm{R}} \leq 6$ \\
\hline $\mathrm{B}$ & $6<D_{\mathrm{R}} \leq 12$ \\
\hline $\mathrm{C}$ & $12<D_{\mathrm{R}} \leq 17$ \\
\hline $\mathrm{D}$ & $17<D_{\mathrm{R}} \leq 22$ \\
\hline $\mathrm{E}$ & $22<D_{\mathrm{R}}$ \\
\hline $\mathrm{F}$ & Demand exceeds capacity \\
\hline
\end{tabular}

Fig. 3. Service level that considers the vehicle density specified in the HCM

\section{Introduction of the simulation test}

My analyses were carried out for 8 exit- and 7 entry-type cases, each with 2 types of merging and diverging lane lengths. I selected the surveyed sections, on the one hand, according to a shorter length (in harmony with the values set forth in the German standard) and, on the other hand, in consideration of the maximum section lengths applied in the Hungarian design practice. Furthermore, I surveyed each simulation model for several truck rates as well as different entering and exiting traffic flows. In this manner I tried to find an answer to the question whether in the case of identical traffic flow - there is a significant difference in the vehicle density of the influence area in the merging and diverging lanes, and I also surveyed what optimal geometry is expedient to apply in function of the traffic flow and traffic distribution. I designed the required simulation models based on the below-specified parameters. In addition, I also make estimates on the length of the influence area on the basis of the various entries and exits.

The simulations were conducted on 10,250 or $10,500 \mathrm{~km}$ rural sections, depending on the type of entry and exit.

The settings that were applied in the simulation are presented below. The list follows the logical order applied when building the simulation models.

In the course of the simulation runs, I surveyed the following vehicle categories that were entered into the program:

- passenger cars: the vehicle weight is between $800 \mathrm{~kg}$ and $2000 \mathrm{~kg}$, and the vehicle power is between $55 \mathrm{~kW}$ and 160 $\mathrm{kW}$; 
- trucks: the vehicle weight is between $2,800 \mathrm{~kg}$ and $40,000 \mathrm{~kg}$, and the vehicle power is between $150 \mathrm{~kW}$ and $400 \mathrm{~kW}$.

For both vehicle categories I applied the parameters that are built in the program, and I made no changes to them.

Upon the analysis I also covered the impact of the vehicle composition on the interchange elements. For this purpose, I set up several vehicle compositions with different truck rates, in the following breakdown:

- $100 \%$ passenger cars;

- $90 \%$ passenger cars and $10 \%$ trucks;

- $80 \%$ passenger cars and $20 \%$ trucks;

- $70 \%$ passenger cars and $30 \%$ trucks;

- $60 \%$ passenger cars and $40 \%$ trucks.

Two types of highwayramp elements were used for my analyses: exits and entries. The two ramp types were examined along various design methods, which are detailed in the following list:

- K1 type (a): one-lane exit with simple deceleration lane, examined length: 10,250 m, deceleration lane length: $250 \mathrm{~m}$, number of lanes on the running track before the junction: 3 , after the junction 3 , on the junction element: 1 ;

- K1 type (b): deceleration lane length: $380 \mathrm{~m}$, identical with the parameters of the previous set-up;

- K2 type (a): one-lane exit with deceleration lane, examined length: 10,250 m, diverging lane length: $250 \mathrm{~m}$, number of lanes on the running track before the junction: 3 , after the junction 3 , on the junction element: 2 ;

- K2 type (b): deceleration lane length: $380 \mathrm{~m}$, identical with the parameters of the previous set-up;

- K3 type (a): two-lane exit with longer lane change section, examined length: $10,500 \mathrm{~m}$, longer lane change section length: $500 \mathrm{~m}$, number of lanes on the running track before the junction: 3 , after the junction 3 , on the junction element: 2 ;

- K3 type (b): diverging lane length: $760 \mathrm{~m}$, identical with the parameters of the previous set-up;

- K4 type (a): two-lane exit with one lane exit, examined length: 10,500m, the longer lane change section length: 500 $\mathrm{m}$, number of lanes on the running track before the junction: 4 , after the junction 3 , on the junction element: 2 ;

- K4 type (b): longer lane change section: $760 \mathrm{~m}$, identical with the parameters of the previous set-up;

- B1 type (a): one-lane entry with simple merging lane, examined length: 10,250 m, diverging lane length: $250 \mathrm{~m}$, number of lanes on the running track before the junction: 3 , after the junction 3 , on the junction element: 1 ;
- B1 type (b): merging lane length: $380 \mathrm{~m}$, identical with the parameters of the previous set-up;

- B2 type (a): entry narrowed to one lane with simple merging lane, examined length: 10,250 m, diverging lane length: 250 $\mathrm{m}$, number of lanes on the running track before the junction: 3 , after the junction 3 , on the junction element: 2 ( 1 at the entry spot);

- B2 type (b): diverging lane length: 380 $\mathrm{m}$, identical with the parameters of the pr https://ibank.budapestbank.hu/atutalevious set-up;

- B3 type: line connection, examined length 10,500 m, number of lanes on the running track before the junction: 3 , after the junction: 4 , on the junction element: 1 ;

- B4 type (a): two-lane entry with longer lane change section and lane connection, examined length: $10,500 \mathrm{~m}$, the longer lane change section length: $500 \mathrm{~m}$, number of lanes on the running track before the junction: 3 , after the junction: 4 , on the junction element: 2 ;

- B4 type (b): longer lane change section length: 1000 m, identical with the parameters of the previous set-up.

I built up the simulation model of all ramp arrangements a manner that the traffic lane next to the median cannot be used by trucks, and only passenger cars can use this traffic lane.

I placed the exits in the simulation model in a manner that there is a 5000-m-long running track section before the ramp element, and a section of different lengths (4240, 4870 and $5000 \mathrm{~m}$, depending on the ramp arrangement types) was left after the interchange. The model was set up for the entries - in a way similar to exists - by leaving a 5000-m-long running section after the junction. This was necessary as the $5 \mathrm{~km}$ long running track section is already sufficient for checking the impacts of the junction element.

As I surveyed rural highway sections, I set up the models with an intended passenger car speed between 110 and $150 \mathrm{~km} / \mathrm{h}$ and truck speed between 65 and $85 \mathrm{~km} / \mathrm{h}$ on the running track. The speeds intended to be reached at the interchange elements were selected according to the category of the previous or next ramp category, which were the following for the various junction types:

- K1, B1, B3 type ramp elements: passenger cars $80 \mathrm{~km} / \mathrm{h}$ (between 65 - $95 \mathrm{~km} / \mathrm{h}$ ), trucks $80 \mathrm{~km} / \mathrm{h}$ (between $65-85 \mathrm{~km} / \mathrm{h}$ );

- K2 type exit: passenger cars $110 \mathrm{~km} / \mathrm{h}$ (between 90 $130 \mathrm{~km} / \mathrm{h}$ ), trucks $80 \mathrm{~km} / \mathrm{h}$ (between $65-85 \mathrm{~km} / \mathrm{h}$ );

- B2 type entry: passenger cars $90 \mathrm{~km} / \mathrm{h}$ (between 75 $105 \mathrm{~km} / \mathrm{h}$ ), trucks $80 \mathrm{~km} / \mathrm{h}$ (between $65-85 \mathrm{~km} / \mathrm{h}$ );

- K3, K4, B4 type ramp elements: passenger cars $130 \mathrm{~km} / \mathrm{h}$ (between $110-150 \mathrm{~km} / \mathrm{h}$ ), trucks $80 \mathrm{~km} / \mathrm{h}$ (between 65 $85 \mathrm{~km} / \mathrm{h})$; 
The speed ranges were established in a manner that the permitted speed was V85, i.e. the speed that is not exceeded by $85 \%$ of the drivers, thus in the course of the simulation the vehicles proceeded at a speed conforming with the realistic traffic situation.

As my analysis was focused on rural highway sections, I applied the Wiedemann 99 car following model [9, 10], recommended in the user manual [7] of the VISSIM program. In the Wiedemann model, the vehicles following each other continuously change their speed according to the speed of the vehicle travelling in front of them. A faster vehicle reduces its speed as it nears, and then catches up with a slower vehicle. The vehicle earlier travelling at a higher speed reduces its speed to a speed slower than that of the slower vehicle, then the faster vehicle tries to increase its speed until it once again catches up with the vehicle travelling in front of it. Therefore, the vehicles continuously change their speed according to the given traffic situation.

I used the following traffic (per direction) for determining the number of passing vehicles:

- K1, K2 and K3 type exits: 3600/4350/5100 v/h;

- K4 type exits: 4800/5800/6800 v/h;

- B1, B2 and B3 type entries: the traffic was determined in a manner that the total traffic after the entry should be identical with the entering traffic applied at the $\mathrm{K} 1, \mathrm{~K} 2$ and $\mathrm{K} 3$ type exits;

- B4 type entry: the traffic was determined in a manner that the total traffic after the entry should be identical with the entering traffic applied at the $\mathrm{K} 4$ type exits;

The above traffic values conform with the value pertaining to the permitted, tolerable traffic flow between the two, as specified in the relevant road technical prescription [5]. As the relevant standard specifies the traffic flows in $\mathrm{pc} / \mathrm{h}$ unit, those must be converted to $\mathrm{c} / \mathrm{h}$ unit. The slight deviation from the standard values was caused by this conversion, as I used round traffic flows for $50 \mathrm{c} / \mathrm{h}$ value upon the simulation. The purpose of running the wide-spectrum traffic flow was to determine the impact of traffic flow on the change in the number of passing vehicles.

Apart from traffic flow and traffic composition, another important element - with regard to ramp elements - is what percentage of the vehicles passing the running track section exit at the junction. In order to survey the impact of this factor on the number of passing vehicles, the simulation runs were also carried out for 20, 30 and $40 \%$ exit traffic. At the entries, the rate of traffic travelling on the running track and intending to enter at the junction branch was 20,30 and $40 \%$.

The applied program provides the chance to give the traffic flow certain stochastical with the help of the factor named stochastic co-efficient - as a result, the simulation and the deriving results better reflect the reality. All traffic flows were also examined with 10, 20,30, 40 and 50 stochastic co-efficients, thus ensuring a larger sampling opportunity that renders the results more accurate (the program would offer the chance to apply an unlimited number of stochastic co-efficients but the time need of simulation runs and the quantity of the data to be evaluated increase proportionately with increasing the stochastic coefficient).

The simulation runs were made on a $4500 \mathrm{~s}$ time interval. Of this, the first 900 s serve the fill-up of the road section with vehicles, thus, in the evaluation period I was already able to analyze the traffic situation that is intended to be examined. I used a onehour interval between $900 \mathrm{~s}$ and $4500 \mathrm{~s}$ for the evaluation. The above time values do not represent simulation seconds but they are real-time seconds.

When carrying out the simulation, the number of passing vehicles was specified according to lanes and to 50-meter sections between the beginning and the end of the road section in the various models. To determine this, I carried out a total of 3375 simulation runs in 15 various arrangements (exits and entries in total), in consideration of various traffic sizes and stochastic co-efficients. These results provided me with the opportunity to draw the appropriate conclusions.

\section{Results of the simulation runs}

In the first step I examined the simulation models - specified in the previous paragraph - based on the number of passing vehicles. I specified the number of passing vehicles according to $50 \mathrm{~m}$ in each lane. Afterwards I determined the vehicle density emerging in each lane by converting the passing number of vehicles from $\mathrm{c} / \mathrm{h}$ to $\mathrm{pc} / \mathrm{h}$ (trucks were considered at a 2.5 rate [4]), I calculated an average from the number of passing vehicles projected to a $1 \mathrm{~km}$ section, then I illustrated the results on a longitudinal section, which are presented by the following graphs according to various junction elements and traffic flows. The vertical axis of the graphs shows the vehicle density in $\mathrm{pc} / \mathrm{h} / \mathrm{lane}$ unit, and the horizontal axis shows the site plan sectioning. The thickness and the pattern of the lines illustrated in the graphs show the number of lanes (the thick, continuous line is the nearside (right-hand) lane, the medium-thick, widely broken line stands for the middle lane, and the thin, closely broken line represents the lane next to the median), while the colors show various traffic flows and traffic compositions (the line color darkens parallel with the increase in traffic size). On the horizontal axis of the graphs, the sectioning only starts from the $1+000 \mathrm{~km}$ section as the density of traffic lanes can only be interpreted only after a length of $1000 \mathrm{~m}$. The vertical thick line in the graphs indicates the start of the diverging lane for exits as well as the connection point of the main track and the junction branch for entries.

In order to facilitate the interpretation of the large number of graphs, I explain a few characteristics through a large graph.

Figure 4 shows an exit case. The thick, black line is the start of the diverging lane, the thick, closely broken line is the end of the diverging lane, while the widely broken, thick line represents the start of the influence area. The figure goes to show that the 


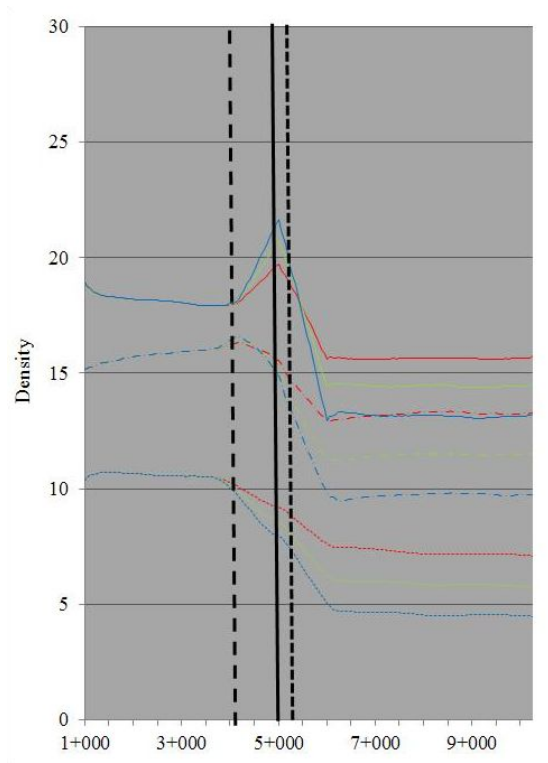

Fig. 4. Sample assisting the interpretation of the simulation results

vehicle density can be regarded as almost constant in each lane up to the start of the influence area. Thus, lane changes in this section due to slower vehicles cannot be indicated in the longitudinal section that illustrates density. However, nearing the exit, the vehicles start looking for their place among the lanes. Vehicles intending to exit start switching to the nearside lane 1 . This lane-changing intention increases upon nearing the deceleration lane, and together with this, the number of vehicles increases due to the exiting traffic. Therefore, after the exit, the vehicles continuing on the running track start moving towards the offside (left-hand) lanes, but this increases the vehicle density in the offside lanes to a smaller extent because lanes 1-3 are available to those who continue to drive on the main track, while exiting vehicles only use lane 1 in the final stage. The foregoing is illustrated in the graph in a manner that the vehicle density decreases in lane 3 when nearing the exit. In lane 2, the vehicle density increases - slightly though - when nearing the exit due to the fact that the vehicles that continue to drive on the main track change lane in order to bypass the vehicles that are already driving at a lower speed because they intend to exit in lane 1 . The largest impact of the nearing exit on vehicle density can be seen in lane 1 , as this lane collects the vehicles intending to exit and some of the vehicles that continue to drive on the main track. This vehicle density increase is shown by the ascending vehicle density line within the influence area, which continuously increases until the lane is changed, and when the lane-changing spot is left, it falls back to a figure that is lower than the starting value. This latter phenomenon is due to the fact that the traffic on the main track is reduced after the exit. Having set forth the above, I am going to present my results deriving from the large number of simulation runs.

In Figures 620 the growth of traffic flow decreases average speed as noticeable earlier analyses [2].

Figure 5 shows the legend applied in the graphs that present the results.

Figures 6 and 7 show the simulation results of the K1 type exit for $250 \mathrm{~m}$ and 380-m-long diverging lanes.

Figures 6 and 7 show that in the case of a 250-m-long diverging lane the influence area is $1000 \mathrm{~m}$ in lane 1 and $1500 \mathrm{~m}$ in lane 2, however, the caused impact is different: $10-20 \%$ in lane 1 , and only 5-6\% in lane 2 , depending on the traffic composition. Looking at the lengths of the diverging lane we can see that the 380-m-long diverging lane causes a higher disturbance in the traffic lanes and at a longer length. In the case of a 250-m-long diverging lane and a low traffic flow before the influence area, the service level (considering the HCM figures) is $\mathrm{B} / \mathrm{D}$, with an increasing turning traffic rate, as well as $\mathrm{C} / \mathrm{D}$ in the influence area. In the case of a high traffic flow, it is $\mathrm{C} / \mathrm{E}$ before the influence area and stays at the $\mathrm{C} / \mathrm{F}$ level within the influence area. In the case of a 380-m-long diverging lane and with a low traffic flow, these rates are B/D before the influence area and $\mathrm{C} / \mathrm{E}$ within the influence area, and in the case of high traffic flow, these rates are $\mathrm{C} / \mathrm{E}$ before the influence area and $\mathrm{E} / \mathrm{F}$ within the influence area. Building a longer diverging lane does not constitute an advantage if we consider the service levels as a basis.

The simulation runs were used to examine - in addition to the number of passing vehicles - how the average speed of the passing vehicles changed in every $50 \mathrm{~m}$. Based on this, it can be stated in the case of K1 type exit that no speed reduction can be observed in lane 3 in the neighborhood of the exit. The exit impact is also shown in lanes 1 and 2 already in the speed of vehicles. In both lanes, $6-7 \mathrm{~km} / \mathrm{h}$ speed reduction can be measured with $3600 \mathrm{c} / \mathrm{h}$ traffic flow, and $10-11 \mathrm{~km} / \mathrm{h}$ reduction can be measured in the average speed of passing vehicles in lane 1 , with $5100 \mathrm{c} / \mathrm{h}$ traffic flow and with a high truck rate. The rates were recorded independently from the diverging lane length.

Figures 8 and 9 show the results of $\mathrm{K} 2$ type exit for $250 \mathrm{~m}$ and 380-m-long diverging lanes.

Looking at Figures 8 and 9 we can see that in the case of a 250-m-long diverging lane the K2 type exit has no detectable advantage compared to the K1type exit. However, if we look at the 380-m-long diverging lane, a significant change can be perceived compared to the $\mathrm{K} 1$ type exit. The influence area length remains unchanged, but the range of impacts caused in the lanes shows a more favorable picture. In the case of a 250-m-long diverging lane and a low traffic flow before the influence area, the service level is $\mathrm{B} / \mathrm{D}$, with an increasing turning traffic rate, as well as $\mathrm{C} / \mathrm{D}$ in the influence area. In the case of a high traffic flow, it is $\mathrm{C} / \mathrm{E}$ before the influence area and stays at the $\mathrm{C} / \mathrm{F}$ level within the influence area. In the case of a 380-m-long diverging lane and with a low traffic flow, these rates are B/D before the influence area and $\mathrm{C} / \mathrm{E}$ within the influence area, and in the case of a high traffic flow, these rates are $\mathrm{C} / \mathrm{E}$ before the influence area and $\mathrm{C} / \mathrm{F}$ within the influence area. Building a longer diverging lane does not constitute an advantage even in the case of $\mathrm{K} 2$ type exit if we consider the service levels as a basis. 


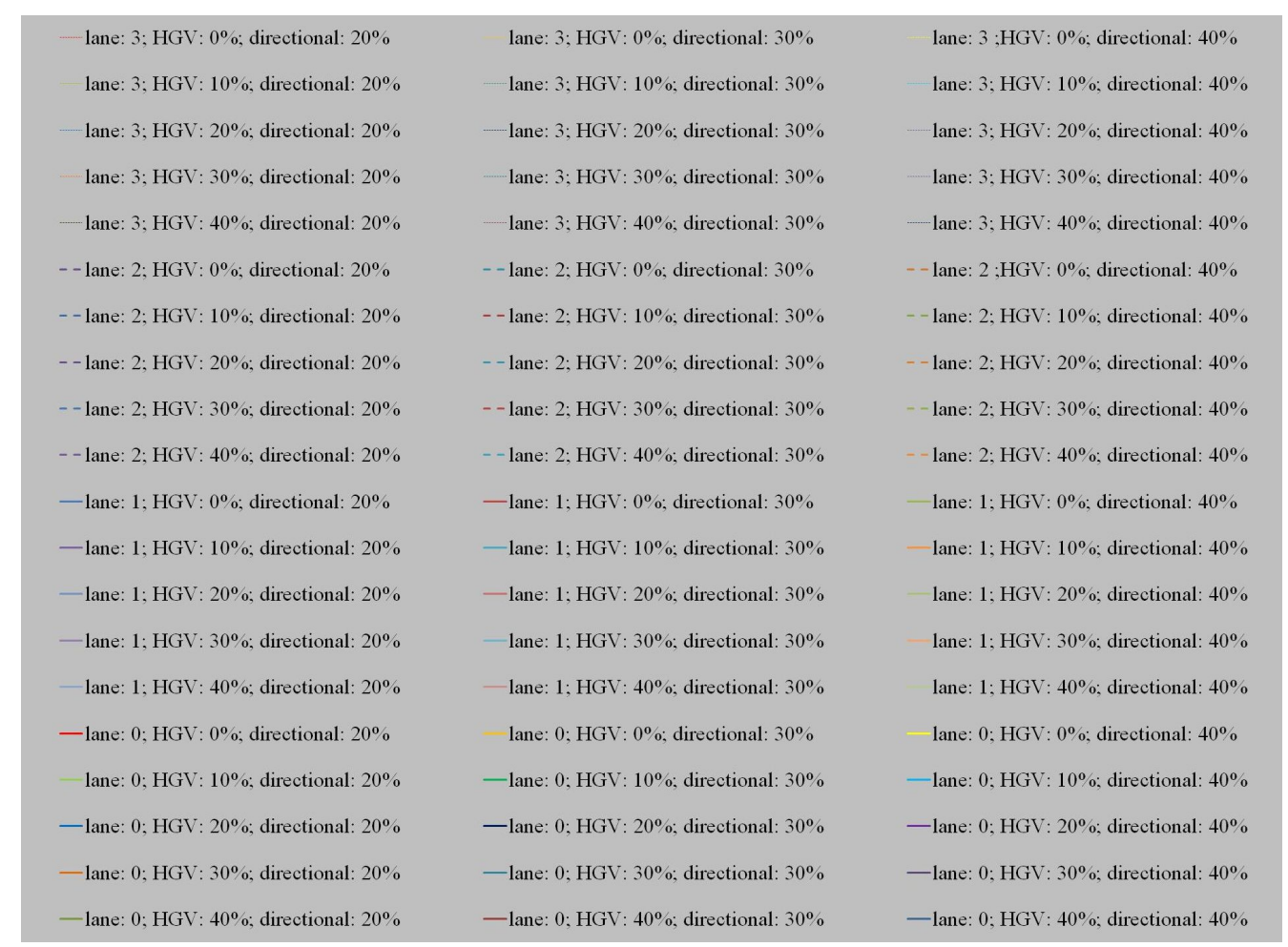

Fig. 5. Legend for the results
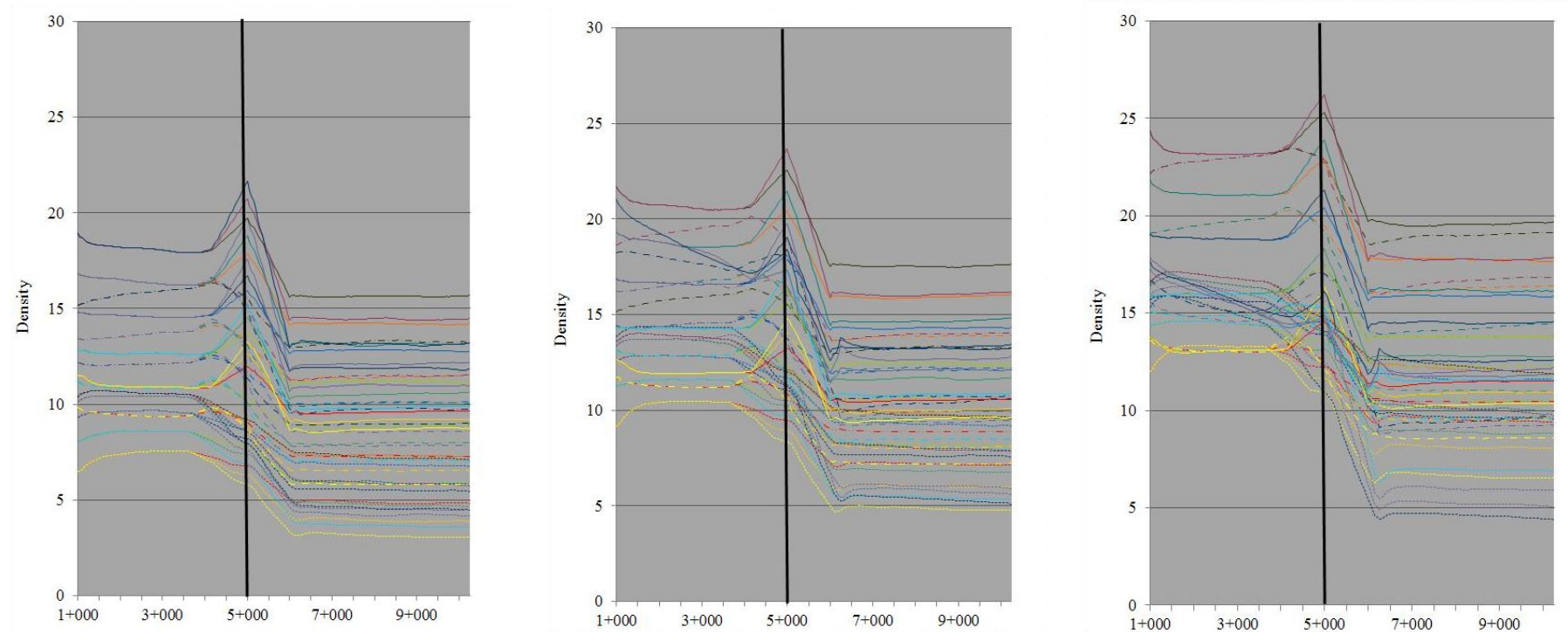

Fig. 6. Vehicle density K1 type exit, 250-m-long diverging lane and 3600/4350/5100 c/h traffic flow 

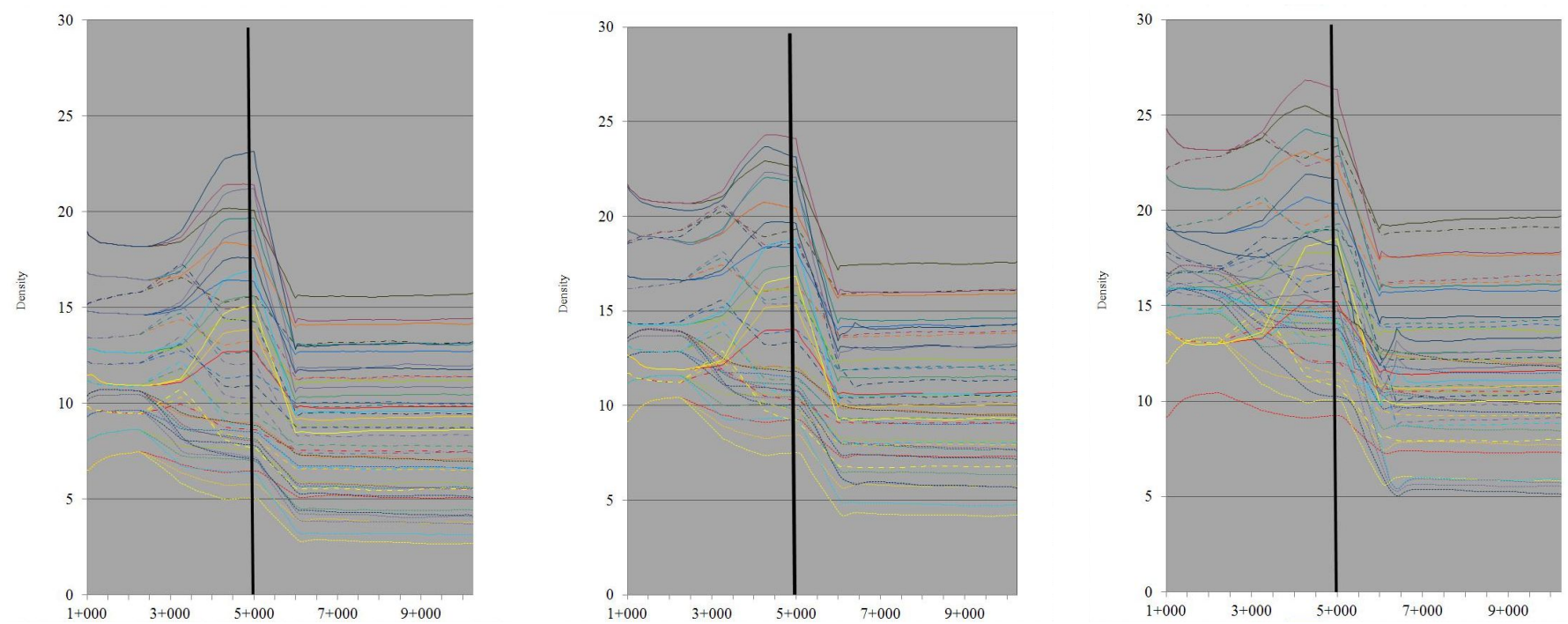

Fig. 7. Vehicle density K1 type exit, $380 \mathrm{~m}$ long diverging lane and 3600/4350/5100 c/h traffic flow
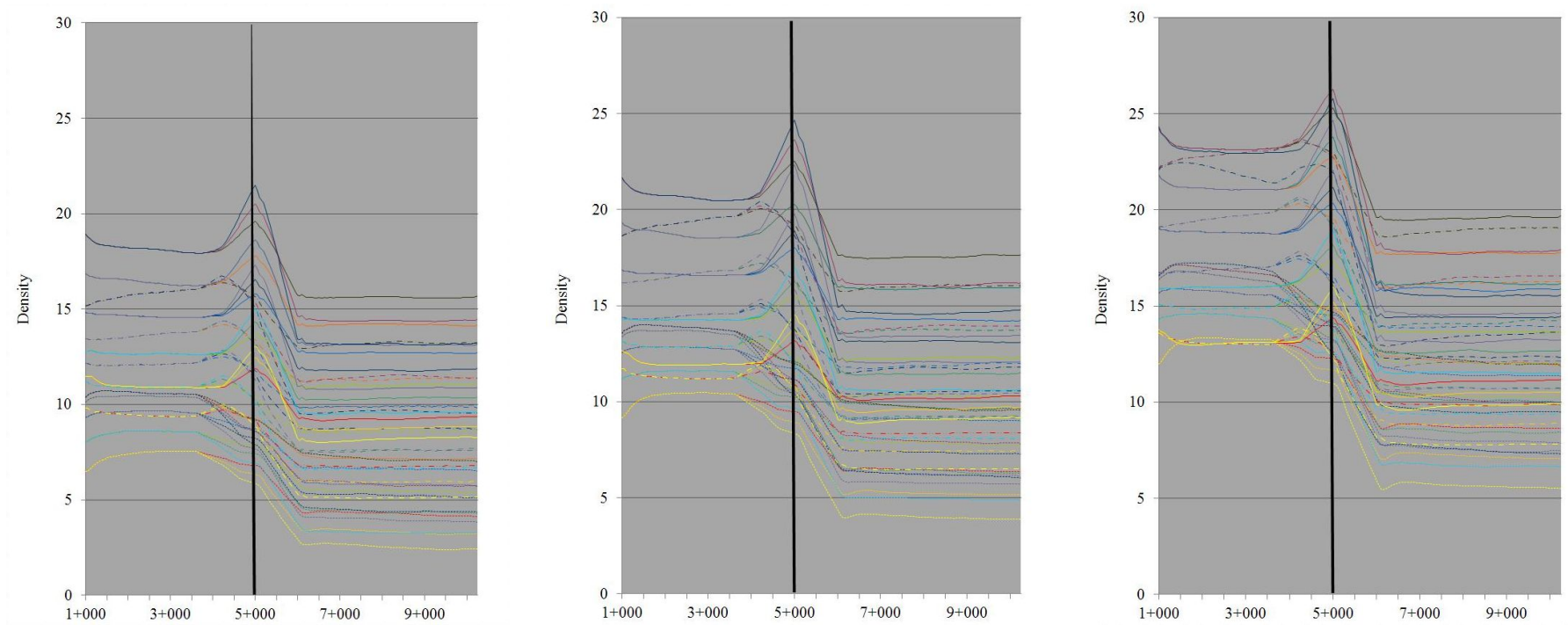

Fig. 8. Vehicle density K2 type exit, 250-m-long diverging lane and 3600/4350/5100 c/h traffic flow
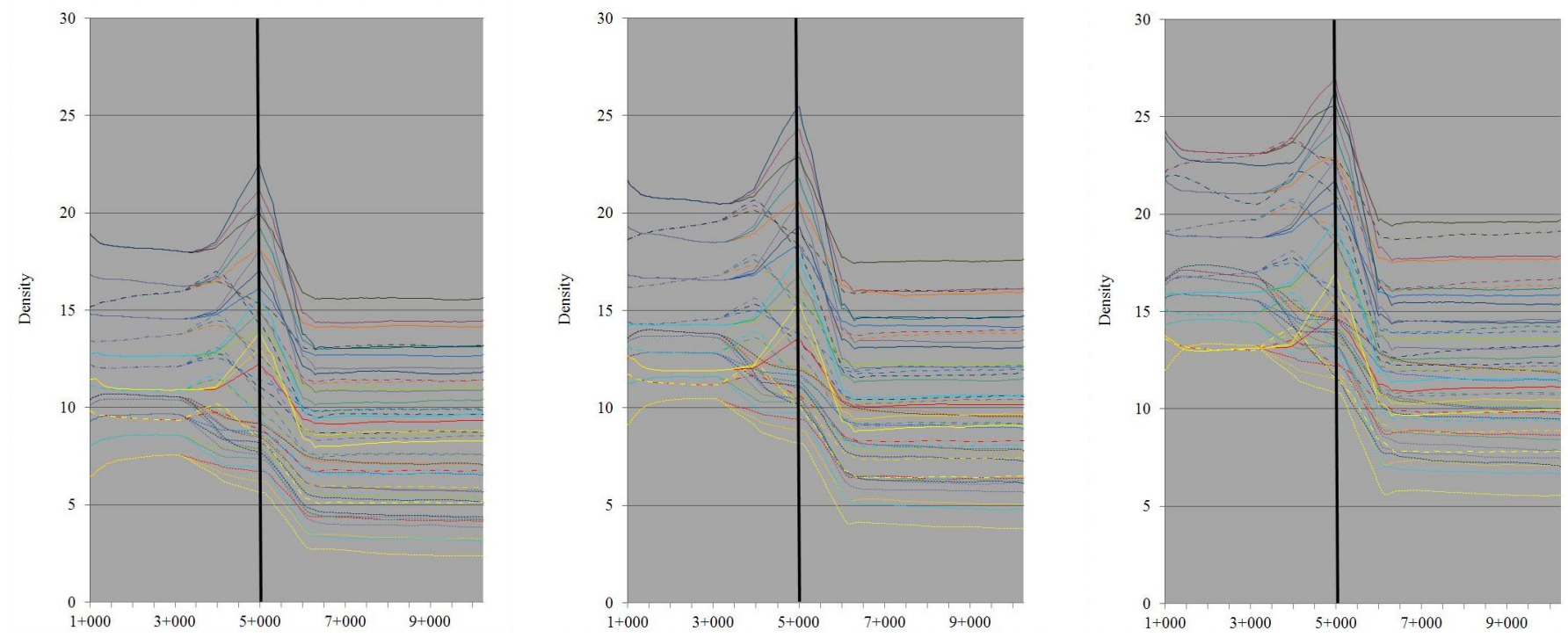

Fig. 9. Vehicle density K2 type exit, 380-m-long diverging lane and 3600/4350/5100 c/h traffic flow 
The impact of $\mathrm{K} 2$ type exit on the change in average speed brought similar results as the K1 type exit, in the case of both shorter and longer diverging lanes.

Figures 10 and 11 present the results of K3-type exits.

Results of the $\mathrm{K} 3$ type exits show a similar picture to the $\mathrm{K} 1$ type exits. However, in this case the 380-meter-long diverging lane does not at all have a positive effect when compared to the results of the 250-meter-long diverging lane, but the degree of effects caused in the separate traffic lanes is much smaller. At the same time, the traffic flow shows a decreasing tendency within the influence area. In the case of a 500-meter-long longer lane change section lane, the length of the influence area is $1200 \mathrm{~m}$ in lane 1, but as much as $1700 \mathrm{~m}$ in lane 2, and in the case of a 760 -meter-long longer lane change section lane, it is $1900 \mathrm{~m}$ in both lanes 1 and 2. In summary, it can be stated that constructing longer lanes does not bring advantages in the case of $\mathrm{K} 3$ type exits. In the case of both longer lane change section lane lengths, the service level is $\mathrm{B} / \mathrm{C}$ before the influence area under low traffic flow and when increasing the rate of turning traffic, while it is $\mathrm{B} / \mathrm{D}$ in the influence area. In the case of high traffic flow, it is $B / D$ before the influence area, and $C / E$ in it. When we consider the service levels, then constructing longer lanes does not bring advantages.

When considering the average speed, then there is no decrease in speed in lane 3 . in the case of a K3 type exit. The effect of the exit shows in lanes 1 and 2 as far as the speed of the vehicles is concerned. A speed decrease of $4-5 \mathrm{~km} / \mathrm{h}$ can be observed in both lanes at a traffic flow of $3600 \mathrm{c} / \mathrm{h}$, but at a traffic flow of $5100 \mathrm{c} / \mathrm{h}$ and a high rate of trucks, $5-6 \mathrm{~km} / \mathrm{h}$ slower average speed is measured in lane 1 , irrespective of the length of the longer lane change section lane.

Figures 12 and 13 present the simulation results of $\mathrm{K} 4$ type exits.

Looking at the results, it can be stated that - similarly to K3 type exits - constructing longer lanes does not bring any advantages. Length of the influence area is $1200 \mathrm{~m}$ in lane 1 in the case of a longer lane change section of $500 \mathrm{~m}$. The exit's effect on vehicle traffic is almost negligible in lane 2 and in lane 0 (that is dissolved after the exit). In the case of a 760-meter-long longer lane change section, the length of the influence area is identical to the value measured in the case of a 500-meter-long longer lane change section, but the effect on traffic is more significant in each traffic lane. In the case of a 500-meter-long the longer lane change section, the service level is $\mathrm{B} / \mathrm{D}$ before and in the influence area under low traffic flow conditions irrespective of the turning traffic. In the case of high traffic flow, the level is $\mathrm{C} / \mathrm{D}$ before the influence area, and $\mathrm{C} / \mathrm{E}$ in it. The same values are $C / D$ before and in the influence area in the case of a 760-meter-long longer lane change section under low traffic conditions, and under high traffic conditions it was C/D before, and $\mathrm{C} / \mathrm{E}$ in the influence area. If we consider service levels, then constructing a longer lane does not bring any advantages even in the case of $\mathrm{K} 4$ type exits.
With respect to the average speed of vehicles, results of the $\mathrm{K} 4$ type exits are similar to those of $\mathrm{K} 3$ types, but I have examined the $\mathrm{K} 4$ type exit with an increased traffic flow.

Now, I am going to present the results of the entries. First of all, Figures 14 and 15 present the results of B1 type entries.

The graphs presenting the results of B1 type entries show that in case of a 250-meter-long merging lane, the influence area is 2000 meters long, while in the case of a 380-meter-long merging lane, the effects of entry can be shown only on 1600 meters. The effect on the traffic in lane 2 is almost negligible both in the case of the shorter and the longer merging lanes. If we observe the length of the influence area, then the longer merging lane can significantly decrease the disturbed traffic situation caused by the entry. In the case of both merging lane lengths, the service level is $\mathrm{B} / \mathrm{D}$ before and in the influence area under low traffic flow upon increasing the rate of diverging traffic, while it is $\mathrm{B} / \mathrm{E}$ before and in the influence area in the case of high traffic flow. If we consider the service levels, then constructing longer merging lanes does not bring advantages even in the case of a B1 entry.

In the case of B1 entry, the effect of the entry can only be observed with respect to the average speeds. What can be observed in lanes 2 and 3 is that the average speed decreases due to the larger traffic flow emerging on the running track after entry, but this change is continuous, local decrease in speed cannot be observed in the influence area of entry. The speed decrease measured in lane 1 . in the case of a 250-meter-long merging lane is as low as $6-7 \mathrm{~km} / \mathrm{h}$, and it is $10-12 \mathrm{~km} / \mathrm{h}$ under high traffic flow, while the same values are $2-3 \mathrm{~km} / \mathrm{h}$ and $7-8 \mathrm{~km} / \mathrm{h}$ in the case of 380 -meter-long merging lanes, therefore, the advantage of the merging lane is proven from the respect of speed change.

Figures 16 and 17 show the vehicle density in the case of B2 type entries considering the length of the two types of merging lanes.

Results of the B2 type entries are practically identical to those of the B1 type entries. Reportable advantages may occur on the junction branch, but I only analyzed the effects measured on the running track during my investigation. In the case of both merging lane lengths, the service level is $\mathrm{B} / \mathrm{D}$ before and in the influence area under low traffic flow upon increasing the rate of diverging traffic, while it is $\mathrm{B} / \mathrm{E}$ before and in the influence area in the case of high traffic flow. If we consider the service levels, then constructing longer merging lanes does not bring advantages even in the case of a B2 entry.

In the case of the B2 type entry, the analysis of speed change brought similar results compared to B1. Longer merging lanes can have reportable advantages.

Figure 18 presents the results of B3 type entries. I have examined the B3 type entry with only one layout, since one lane joins the 3 lanes of the running track, and the extended 4-lane cross-section is sustained all the way through on the section after the junction. Thus, the various longer lane change sections lane lengths could not be interpreted.

When analyzing the results of B3 type entries, we can state 

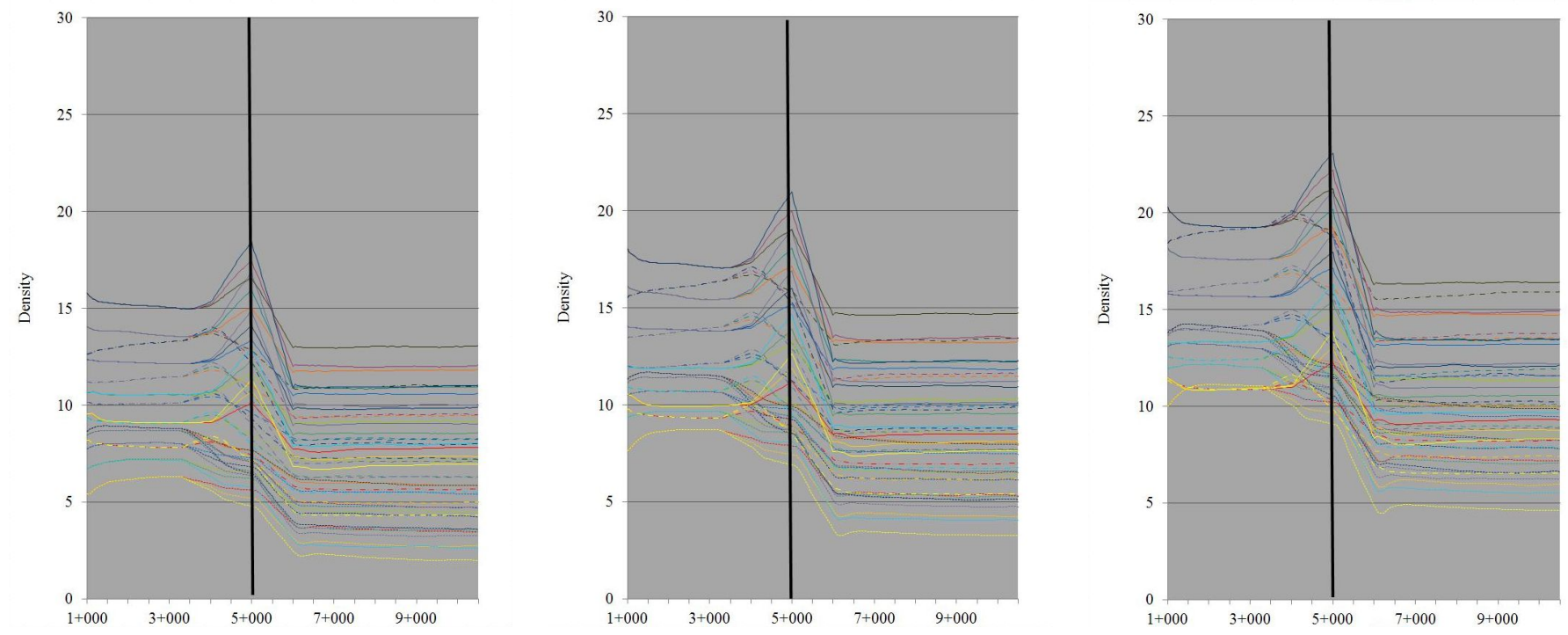

Fig. 10. Vehicle density in the case of a K3-type exit, 500-meter-long lane and a traffic flow of 3600/4350/5100 c/h
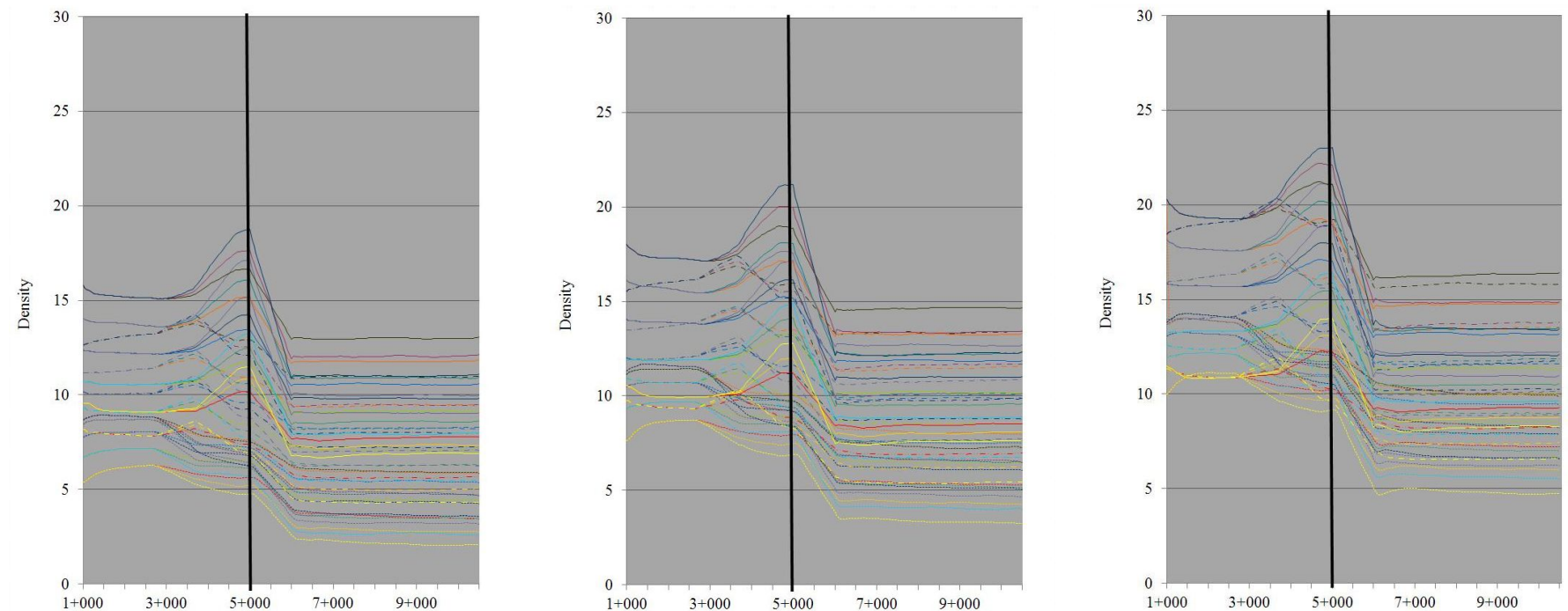

Fig. 11. Vehicle density in the case of a K3-type exit, 760-meter-long longer lane change section and a traffic flow of 3600/4350/5100 c/h
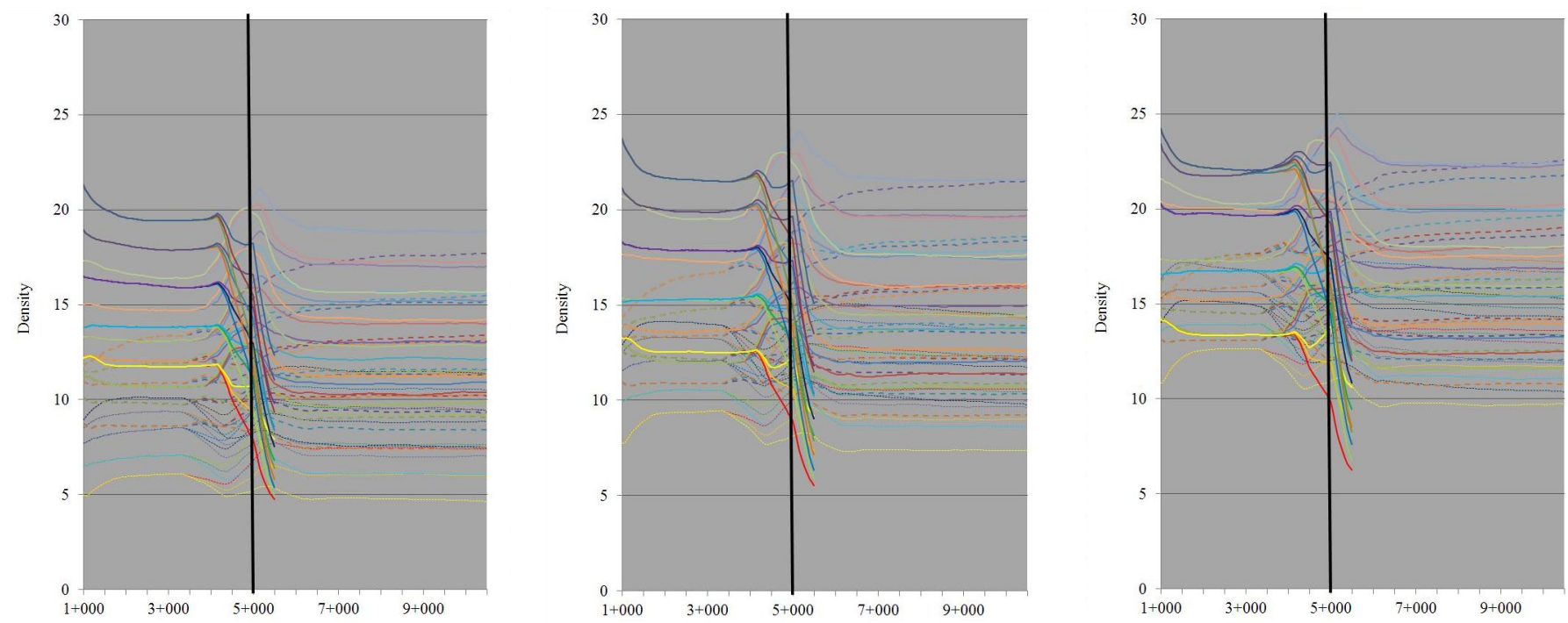

Fig. 12. Vehicle density, in the case of a K4 type exit, 500-meter-long longer lane change section and a traffic flow of 4800/5800/5800 c/h 

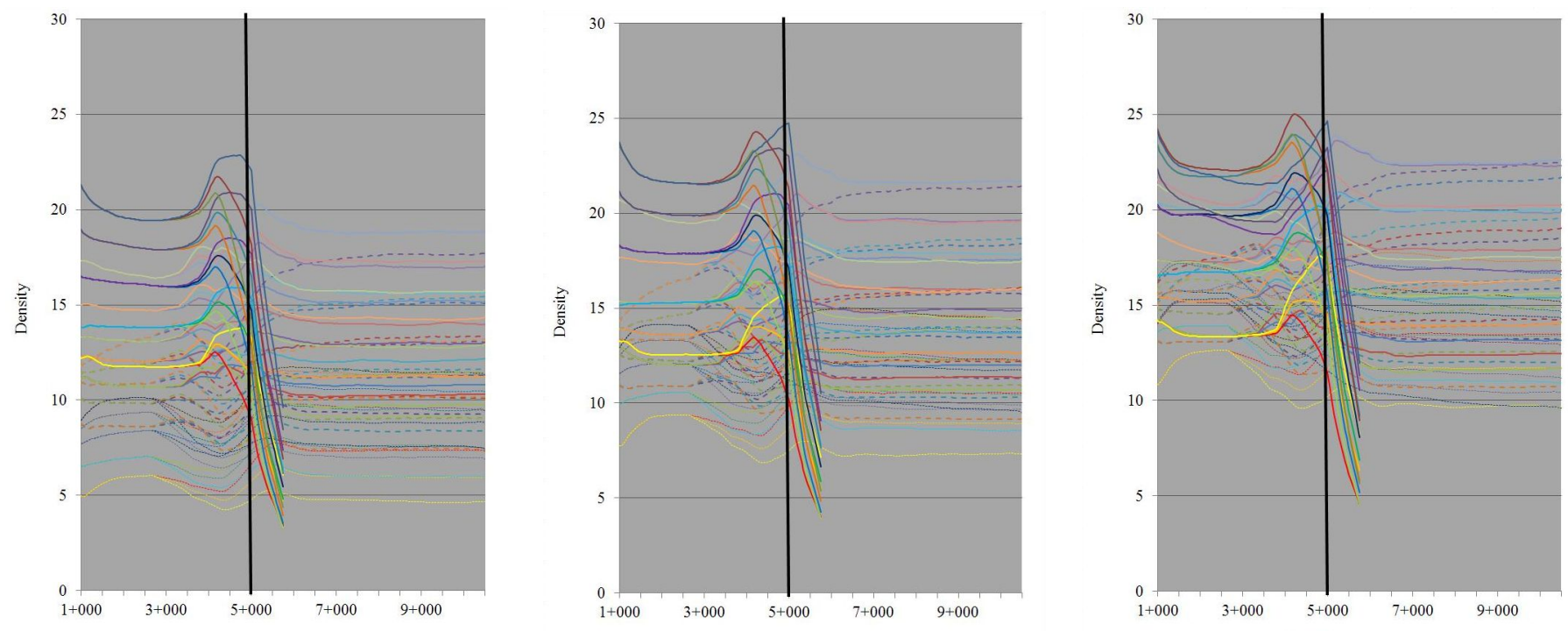

Fig. 13. Vehicle density in the case of a K4 type exit, 760-meter-long longer lane change section lane and a traffic flow of 4800/5800/6800 c/h
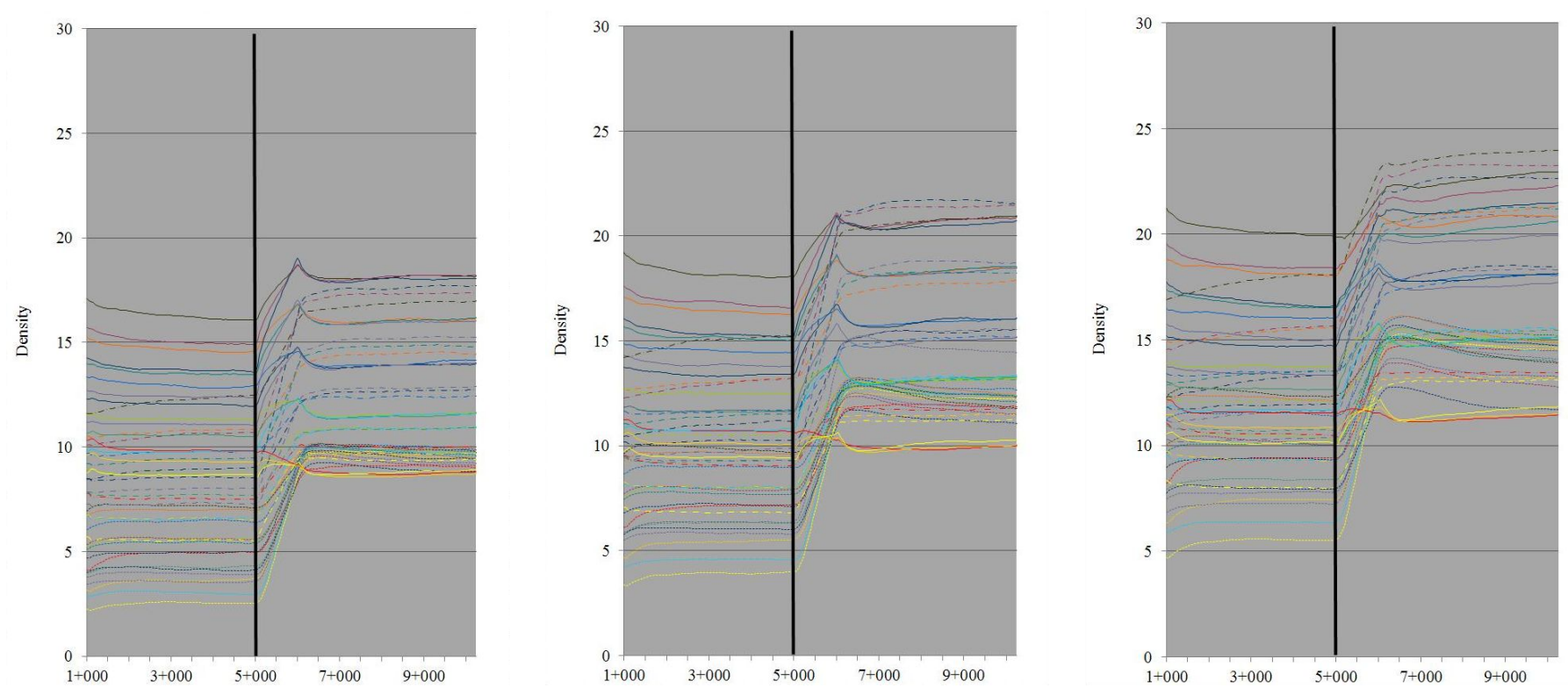

Fig. 14. Vehicle density in the case of a B1 type entry, 250-meter-long diverging lane and a traffic flow of 3600/4350/5100 c/h 

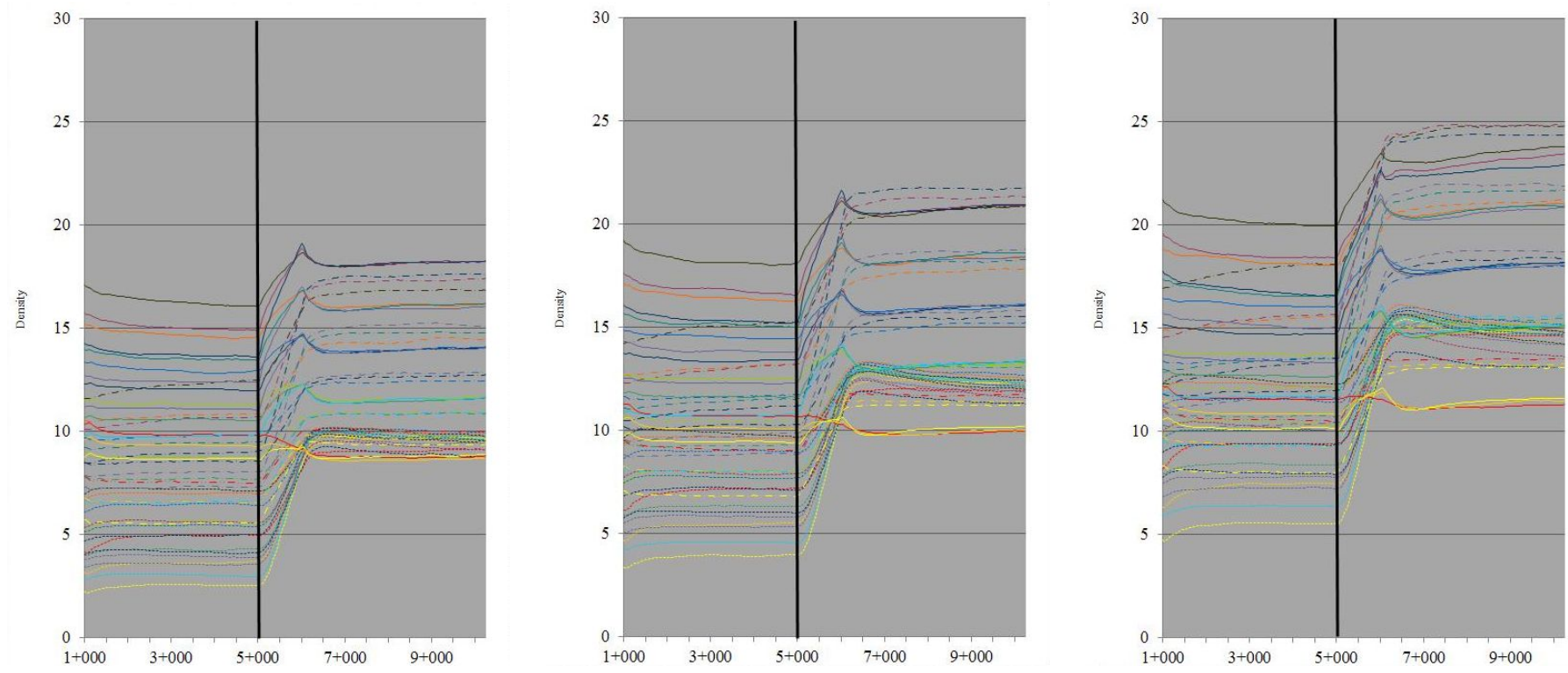

Fig. 15. Vehicle density in the case of a B1 type entry, 380-meter-long diverging lane and a traffic flow of 3600/4350/5100 c/h
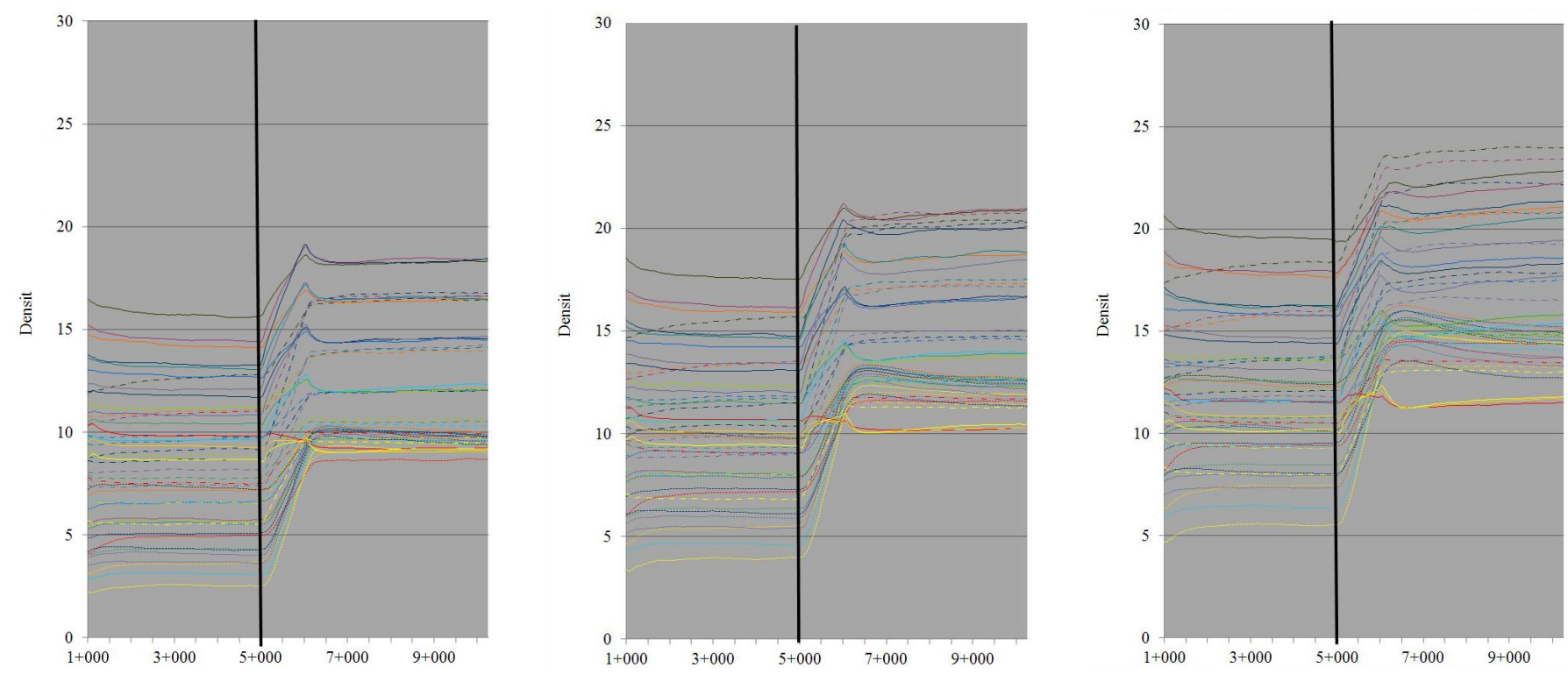

Fig. 16. Vehicle density in the case of a B2 type entry, 250-meter-long diverging lane and a traffic flow of 3600/4350/5100 c/h
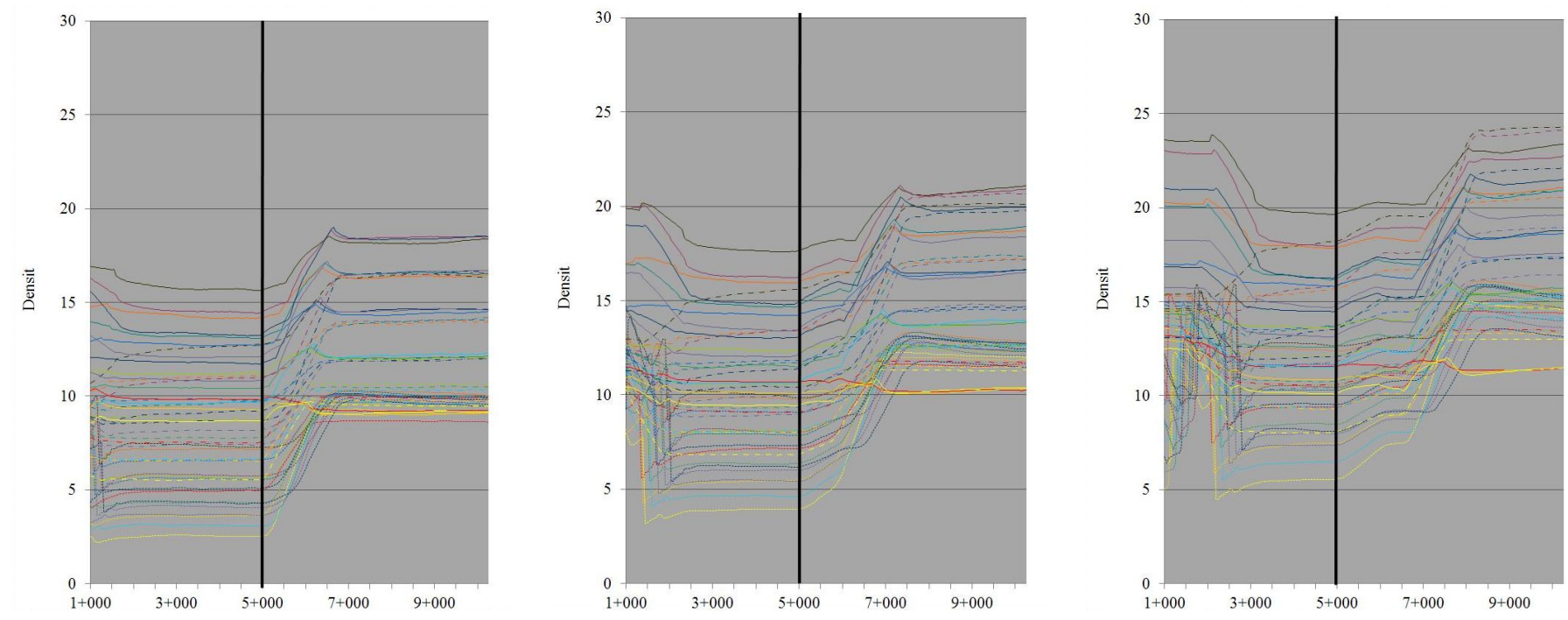

Fig. 17. Vehicle density in the case of a B2 type entry, 380-meter-long diverging lane and a traffic flow of $3600 / 4350 / 5100 \mathrm{c} / \mathrm{h}$ 

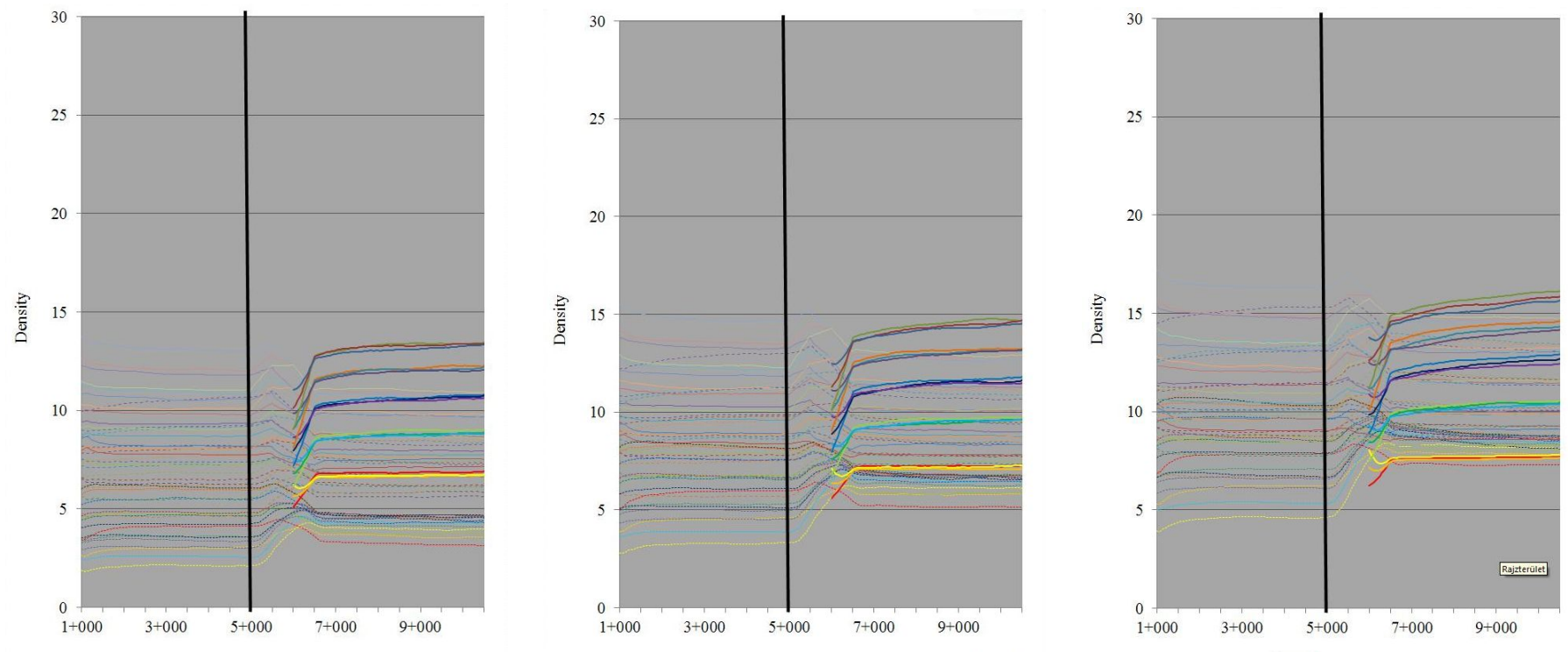

Fig. 18. Vehicle density in the case of a B3 type entry and a traffic flow of $3600 / 4350 / 5100 \mathrm{c} / \mathrm{h}$
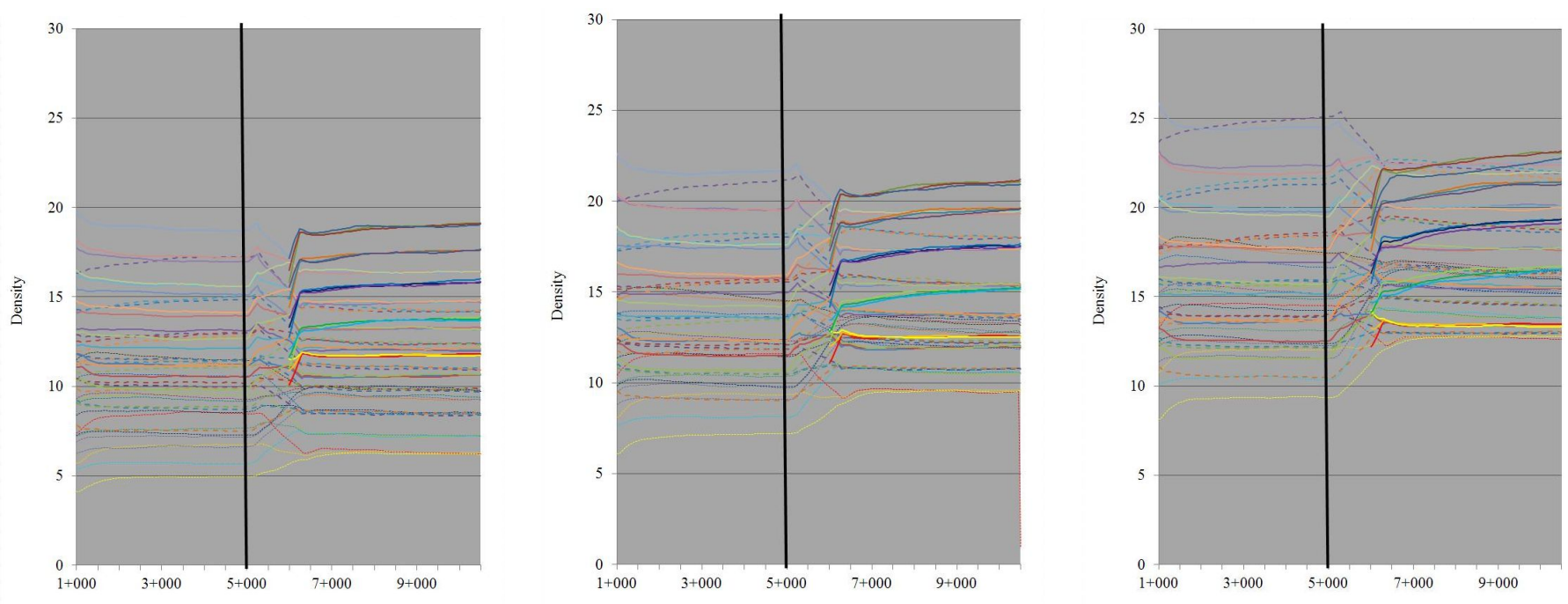

Fig. 19. Vehicle density in the case of a B4 type entry, 500-meter-long longer lane change section and a traffic flow of 4800/5800/6100 c/h
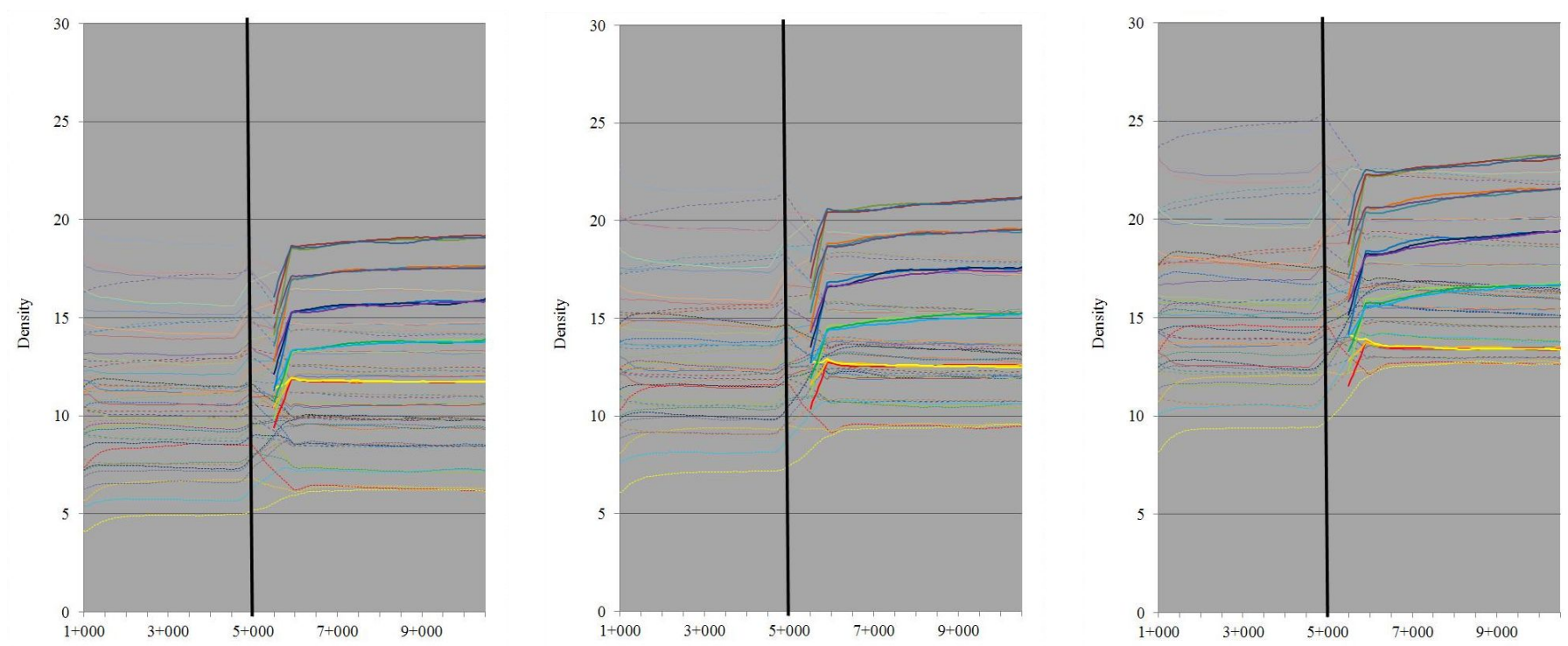

Fig. 20. Vehicle density in the case of a B4 type entry, 1000-meter-long longer lane change section lane and a traffic flow of 4800/5800/6100 c/h 
that the influence area is estimated at 1500 meters from the point of entry, and the entry has reportable effect on the traffic of all traffic lanes. The service level in the influence area is $\mathrm{A} / \mathrm{C}$ and then $\mathrm{A} / \mathrm{B}$ in the case of low traffic flow irrespective of the increasing rate of the turning traffic, while in the case of a high traffic flow, the level is $\mathrm{B} / \mathrm{C}$ in the influence area and after it as well.

In the case of B3 entry types, speed changes can only be measured in lane 1 . In the case of a traffic flow of $3600 \mathrm{v} / \mathrm{h}$, the average speed decreases by $4-5 \mathrm{~km} / \mathrm{h}$, and in the case of a density of $5100 \mathrm{v} / \mathrm{h}$, it decreases by $5-6 \mathrm{~km} / \mathrm{h}$.

Figures 19 and 20 present the results of B4 type entries.

The graphs presenting the results of B4 type entries show that no reportable disturbing effects can be presented in any lane at the examined traffic flows either in the case of observing the longer or the shorter lane constructions. In the case of a 500meter-long the longer lane change section, the service level is $\mathrm{B} / \mathrm{C}$ before and in the influence area under low traffic flow conditions irrespective of the turning traffic. In the case of high traffic flow, the level is C/D before and in the influence area. In the case of a 1000-meter-long longer lane change section, the same values are $\mathrm{B} / \mathrm{D}$ in the influence area under low traffic conditions, and $\mathrm{B} / \mathrm{C}$ after the influence area, and, in the case of high traffic flow, it is $\mathrm{C} / \mathrm{E}$ in the influence area and afterwards as well. When we consider the service levels, then constructing longer lanes does not bring advantages even in the case of B4 type entries.

When analyzing the average speeds, it is revealed that the continuously slower speeds cannot be observed in lanes 2 and 3 in the case of B4 type entries as opposed to B1-B3 types. In lane 3 , the average speed can practically be regarded as constant. In lanes 1 and 2 , the speed decrease was $2-5 \mathrm{~km} / \mathrm{h}$.

When analyzing all results, it is visible that the length of 450 meters applied on the range in HCM based on the results of simulation tests are significantly larger, and the effects of the junction elements cannot only be shown in the two nearside lanes, but also in the traffic lane beside the median.

The results of the simulation tests show that certain exit and entry types cannot bear high traffic, while other types have unreasonable reserves of capacity in the case of low traffic flow. Below I will collect the junction element types recommended for various traffic flows and traffic compositions.

\section{Conclusions}

When studying the results, it is clear that the influence area of the disturbed traffic situation arising due to exiting or entering under all the examined entry and exit constructions is significantly larger than the influence area included in the design practices in the US. The difference may as well be two to four times larger based on the simulation tests.

When examining the exits, we can see that the effect of $\mathrm{K} 1$, $\mathrm{K} 2$ and $\mathrm{K} 3$ type exits on the traffic flow is identical to the effects of K1 K2 designs. The effect of K3, however, is smaller com- pared to the $\mathrm{K} 1$ and $\mathrm{K} 2$ type exits, that is, it has larger capacity reserves under the same traffic conditions, therefore, the application of this exit may be justified in the case of higher traffic flows. However, when analyzing K4 type exits, then, in spite of the fact that this type was analyzed under larger traffic flow, the effects of exiting are hardly noticeable. When observing the values of service levels, then, in the case of exits, we can see that $\mathrm{K} 1$ and $\mathrm{K} 2$ types represent identical levels irrespective of traffic flow, the composition of traffic and the density of the exiting traffic. Comparing to these values, the application of K3 type exits decreases service levels with one grade in the case of high traffic flow. K4 type exits brought similar results to the K1 - K2 type exits, but in the case of significantly higher traffic flows.

When observing the entries, we can see minor differences. Traffic flow does not change in the case of B1 and B2 type entries depending on the length of the merging lane, and I received similar results from the two entries. Compared to the previous two types, B3 type entries bring significant drop in vehicle density under identical traffic flow. The drop is about $20 \%$. When comparing B4 type entry to the B3 type, then we can see that the values are nearly identical, but the traffic flow is higher for the B4 type, thus the B4 type can handle higher entering traffic. Additionally, we can also state that the longer lane did not bring any improvement over the shorter lane in the case of B4. Upon analyzing the service levels of entries, it is obvious that B1 and B2 types bring completely identical results. Compared to them, B3 brings improvement by one service level grade. B4 type entry is slightly lower when compared to B1 and B2 types under low traffic conditions, irrespective of the length of the longer lane change section lane, while it shows a slight increase in the case of high traffic flow, however, higher traffic crossed the junction.

\section{Further investigation opportunities}

I can see further research opportunities in the subject matter of my investigation. The accuracy of the results could be further increased by the simulation tests of higher traffic flow values and by using lower truck rates, as well as the scale units of exiting and entering traffic flow could also be refined. It would cause results resolution like other analyses [3]. It would also be possible to analyze sections including multiple exits and entries.

\section{References}

$1 \mathrm{Fi} \mathrm{I,} \mathrm{Application} \mathrm{of} \mathrm{traffic} \mathrm{simulation} \mathrm{in} \mathrm{the} \mathrm{design} \mathrm{of} \mathrm{intersection} \mathrm{systems}$ concerning traffic and environment, Periodica Polytechnica, 40(2), (1996), 85-94.

2 Fi I, Galuska J, Recommendations for new capacity values on freeways, Periodica Polytechnica Civil Engineering, 54(2), (2010), 127-136, DOI 10.3311/pp.ci.2010-2.08

3 Fi I, Galuska J, Traffic analysis of two-lane highways, Periodica Polytechnica Civil Engineering, 55(2), (2011), 169-176, DOI 10.3311/pp.ci.20112.09

4 Cross sectional flow of road network 2011., Magyar Közút NZRt., 2011. in Hungarian.

5 ÚT 2-1.201. Road Planning, Technical Specification, The Hungarian Road Society, 2008. in Hungarian. 
6 Design of Grade-separated Junction, Design specification No. 11, The Hungarian Road Society, 2006. in Hungarian.

7 VISSIM 5.40-01 - User Manual, PTV VISION, 2012.

8 National Research Council, Highway Capacity Manual, Transport research board (TRB); United States of America, 2010. ISBN 978-0-30916077-3.

9 Wiedemann R, Simulation des Straßenverkehrsflusses, Thesis, Schriftenreihe des Instituts für Vehrkehrswesen der Universität Karlsruhe; Karlsruhe, 1974. language: German.

10 Wiedemann R, Modeling of RTI-Elements on multi-lane roads, In: Commission of the European Community (ed.), Advancad Telematics in Road Transport, Brussels, DG XIII, 1991, pp. 1001-10. 